\title{
Short Segment Versus Long Segment Posterior Pedicle Screws Fixation for Treatment of Thoracolumbar Burst Fracture: A Comparative Prospective Study
}

\author{
Arvind Singh ${ }^{\odot}$, Shiv Kumar Bali ${ }^{\odot}$, Subhajit Maji ${ }^{\odot}$, Kaustubh Ahuja ${ }^{\odot}$, Nagaraj Manju Moger ${ }^{\circledR}$, Samarth Mittal ${ }^{\circledR}$, Bhaskar Sarkar ${ }^{\odot}$, \\ Pankaj Kandwal ${ }^{\odot}$ \\ All India Institute of Medical Science, Rishikesh, Uttarakhand, India.
}

\section{Abstract}

Background: The surgical treatment of unstable burst fracture (TLICS $>4$ ) of the thoracolumbar vertebrae remain controversial. This study is aimed to compare the short segment versus long-segment posterior fixation for thoracolumbar burst fracture.The objective of the study is to study comparison of outcome of the Short-Segment Posterior Fixation (SSPF) versus Long-Segment Posterior Fixation (LSPF) for treatment of thoracolumbar burst fracture in term of surgical, radiological, neurological and functional outcome. Subjects \& Methods: In this prospective study, we included 32 patients with Burst fracture AO type A3, A4 of Thoracolumbar spine (T10-L2), who underwent posterior pedicle screw fixation for Burst fracture Thoracolumbar spine. A total of 18 of the patients underwent Short-Segment Posterior Fixation (SSPF) (Group A); group A is further divided into three subgroups A1: short-segment only(n=10), A2: short-segment with index screw(n=4) and A3: short-segment with anterior column reconstruction $(\mathrm{n}=4)$ with cage, Whereas 14 patients had Long-Segment Posterior Fixation (LSPF) (Group B). Surgical (duration of surgery, blood loss, complication), Clinical (Oswestry questionnaire, spinal cord independent measuring scale), radiological (percentage of anterior body height compression, kyphosis correction loss, Mc Cormack classification) and Neurological (Frankel grading) outcomes were analyzed. Results: The operative time Group A (159.85 $\min \pm 22.5)$ was significantly shorter than Group B (198.7 \pm 31.5 ). Blood loss was significantly less in Group A (478 $\mathrm{ml} \pm 259.3)$ than Group B (865ml \pm 275.7$)$. Kyphosis Correction loss at $6^{\text {th }}$ month follow up in Group A (subgroup A1: $10.7 \mathrm{deg} \pm 6.2$, subgroup A2: 7.1 $\mathrm{deg} \pm 7.4$ and subgroup A3: Subgroup A3: $6.1 \mathrm{deg} \pm 5.2$ ) was higher than that of group B (6.2deg \pm 6.3 ). Complication (surgical site infection) occurred in Two patients in group B. There was no significant difference in terms of improvement in functional and neurological outcomes among both groups. The functional outcomes as per the SCIM and ODI score at $6^{\text {th }}$ month follow up in group A: $74.7+-22.29,31.5+-13.73$ respectively, and group B: 73.8+-26.07, 26.7+-17.9, respectively. Conclusion: Short-Segment Posterior Fixation (SSPF) is a significantly decreased duration of surgery and blood loss compare with Long-Segment Posterior Fixation (LSPF). Loss of kyphosis correction in Short-Segment Posterior Fixation (SSPF) may be decreased with index screws or anterior column reconstruction.

Keywords: Thoracolumbar burst fracture, Short-Segment Posterior Fixation (SSPF), Long-Segment Posterior Fixation (LSPF)

Corresponding Author: Arvind Singh, All India Institute of Medical Science, Rishikesh, Uttarakhand, India.

E-mail: ranaarvindrana@gmail.com

Received: 16 March 2020

Revised: 25 April 2020

Accepted: 31 May 2020

Published: 6 July 2020

\section{Introduction}

Denis et al 1983 defined the burst fracture in his 3-column theory as a compression fracture of the anterior and middle vertebral columns, which causes retropulsion of a posterior vertebral body fragment into the spinal canal. ${ }^{[1]}$ Patients with burst fractures can be managed either conservatively or operatively. Stable injury patterns; Thoracolumbar Injury Classification and Severity Scale (TLICS $<4$ ) may be treated nonoperatively with brace immobilization. Unstable injury patterns (TLICS $>4$ ) are treated operatively with the guiding principles of deformity correction, neurologic decompression if necessary and spine stabilization followed by active patient mobilization. The posterior procedure for the thoracolumbar junction is well established with advantages such as more safety in exploring the surgical site without violating the pulmonary, visceral, and vascular structures, being less technically demanding and familiar to a spine surgeon. ${ }^{[2]}$ Long-Segment Posterior Fixation (LSPF) at least two levels above and below the fractured vertebra. ${ }^{[3,4]}$ Allows for a stronger construct, though limits flexibility at the fractured level and is more extensile and may be associated with higher intraoperative blood loss and length of operation. ${ }^{[5]}$ Short- 
segment fixation has largely replaced long-fixation in the management of burst fractures. However, instrument failure and recurrence of kyphosis are reported if short-segment posterior fixation. ${ }^{[6-8]}$

The implant failure in Short-Segment Posterior Fixation (SSPF) can be circumvented by using an indexing screw in the fractured vertebra or by augmenting posterior fixation with anterior column reconstruction. Several study attempts to compare SSPF with LSPF though each has significant limitations. ${ }^{[9-12]}$

The aim of this study to compare the outcome of SSPF with LSPF in terms of surgical, radiological, functional and neurological outcomes.

\section{Subjects and Methods}

In this prospective study, we included 32 patients fulfilling the inclusion criteria who underwent posterior pedicle screw fixation for Burst Fracture of Thoracolumbar spine.

\section{Inclusion criteria}

- Burst fracture AO type A3, A4

- Thoracolumbar spine (T10-L2)

- TLICS score $>4$

- Mc Cormack score $>7$

A total of 18 of the patients underwent Short-Segment Posterior Fixation (SSPF) (Group A); Group A is further divided into three subgroups A1: short-segment only $(n=10)$, A2: short-segment with index $\operatorname{screw}(n=4)$ and $A 3$ : shortsegment with anterior column reconstruction $(\mathrm{n}=4)$ with cage, whereas 14 patients had Long-Segment Posterior Fixation (LSPF) (Group B). Surgical (duration of surgery, blood loss, complication), Clinical (Oswestry questionnaire, spinal cord independent measuring scale), radiological (percentage of anterior body height compression, kyphosis correction loss, Mc Cormack classification) and Neurological (Frankel grading) outcomes were analyzed.

\section{Surgical technique}

Posterior/ poster lateral approach: After induction of anesthesia, the patient was positioned prone, ensuring adequate padding of bony prominences. Under all aseptic precautions, partly prepared and draped. The incision is given from one or two spinous processes above and below the area to be instrumented. Fascia and the par spinal muscles elevated from lamina up to the tips of the transverse processes. Pedicle screws were inserted one level above and below the fractured vertebra for Short-Segment Posterior Fixation (SSPF) (Group A) and two or more than two levels above and below for Long-Segment Posterior Fixation (LSPF) (Group B) and fixed with the rod on one side provisionally followed by Posterior or Poster lateral decompression and the anterior column was reconstructed using either cage filled with graft or graft alone. Posterior elements and transverse processes decorticated at each instrumented level and placed the bone graft onto the decorticated surface. The contoured rod was placed bilaterally and the wound would be closed in layers over a drain.

\section{Results}

\section{Case examples:}

Case example 1: Short segment posterior fixation with Index screw

Case example 02: Short segment posterior fixation with anterior column reconstruction.

Case example 03: Long segment posterior fixation.

The operative time Group A $(159.85 \pm 22.5 \mathrm{~min})$ was significantly shorter than Group B (198.7 $31.5 \mathrm{~min})$. Blood loss was significantly less in Group A $(478 \pm 259.3 \mathrm{ml})$ than Group B $(865 \pm 275.7 \mathrm{ml})$. Mean Kyphosis correction in Group A (subgroup A1: $12.7 \mathrm{deg} \pm$ 7.2, A2: $13.2 \mathrm{deg} \pm$ 5.2, A3: $16.3 \mathrm{deg} \pm 8.2)$ and Group B (16.8deg \pm 4.2). The kyphosis correction between the groups was comparable in the post-op period. Loss of Kyphosis Correction at $6^{\text {th }}$ month follow up between Group A2 and A3 is comparable to group 3, while in Group A1 was higher than that of Group B [Table 1]. Mean SCIM, and ODI score at $6^{\text {th }}$ month follow up in Group A (A1, A2 \& A3) was: $74.7+-22.29,31.5+-13.73$ respectively and in Group B: 73.8+-26.07, 26.7+-17.9 respectively. There was no significant difference in terms of functional and neurological outcomes [Table 2]. Complication: surgical site infection occurred in two patients in Group B.

\section{Discussion}

Operative treatment for thoracolumbar burst fracture is generally performed when TLICS score more than or equals to 4. The goal of surgery is to decompress the spinal canal, restoration, maintenance of vertebral body height, spinal alignment, rigid fixation for early ambulation and rehabilitation, prevention of progressive neurological injury and kyphotic deformity. Although short-segment pedicle screw fixation is considered as a standard method. ${ }^{[8,13-20]}$ Some studies have shown a higher rate of failure. ${ }^{[21]}$

Our study showed Group A has statistically $(p<0.05)$ shorter duration of surgery as compared to Group B, which is comparable with a study conducted by Sapkas et al. ${ }^{[12]}$ and Tezeren et al. ${ }^{[9]}$ We found blood loss was significantly less $(\mathrm{p}<0.005)$ in Group A $(478 \mathrm{ml} \pm 259.3)$ than Group B (865 $\mathrm{ml} \pm 275.7)$, which is comparable with Sapkas et al. ${ }^{[12]} \&$ Tezeren et al. ${ }^{[9]}$ 

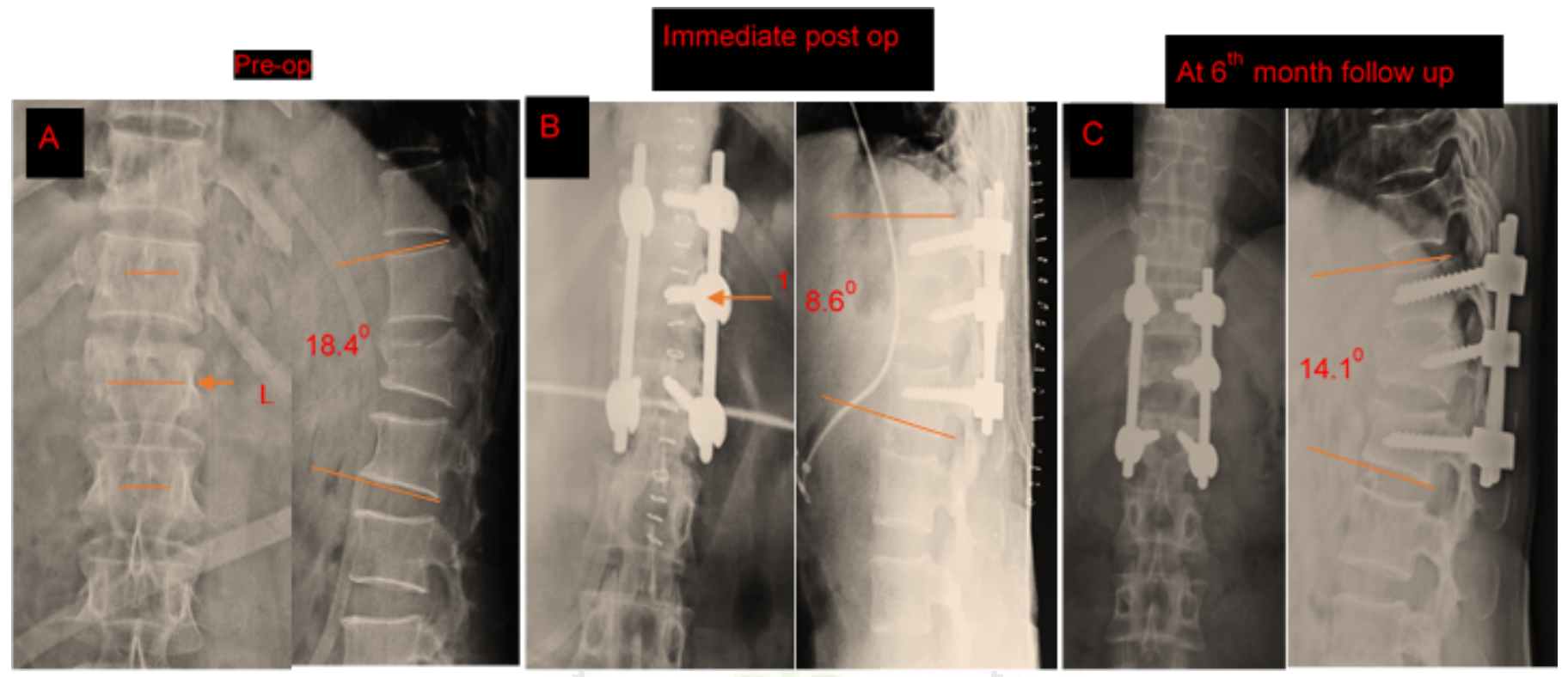

Figure 1: Showing case example of a 34-year-old male with burst fracture L1 with Frankel C paraplegia which was managed with short-segment posterior fixation with index screw:- (A) -pre-operative plan radiograph showing decreased L1 vertebral body height with increased interpedicle distance in AP view which is suggestive of burst fracture L1 with kyphotic deformity of 18.4degree, (B) -plan radiograph postoperative showing short-segment posterior fixation with index screw (arrow) in fracture vertebra with kyphosis angle 8.6 degrees, (C)- plan radiograph at 6th moth follow up showing kyphosis angle of 14.1degree.
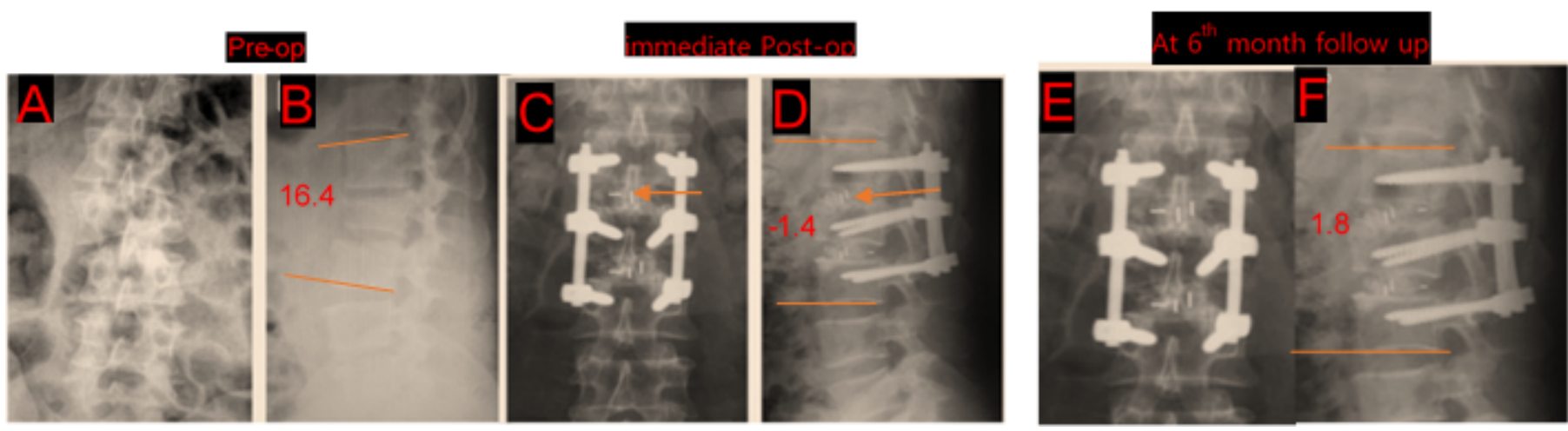

Figure 2: Showing case example of a30-year-old male with burst fracture L1 with Frankel D paraplegia which was managed with short-segment posterior fixation with anterior column reconstruction with PEEK cage:- (A\& B) -pre-operative plan radiograph showing decreased L1 vertebral body height with increased interpedicle distance in AP view which is suggestive of burst fracture L1 with ky-photic deformity of 16.4degree, (C \&D) -plan radiograph postoperative showing short-segment posterior fixation with anterior column reconstruction with PEEK cage (arrow) with lordosis angle 1.4 degree, (E \&F)- plan radiograph at 6th month follow up showing kyphosis angle of 1.8degree. 


\begin{tabular}{|c|c|c|c|}
\hline Radiological outcome & Group A $($ mean \pm SD) & Group B $($ mean \pm SD $)$ & p value \\
\hline \multirow[t]{3}{*}{ Kyphotic correction } & Subgroup A1: $12.7 \mathrm{deg} \pm 7.2$ & $16.8 \mathrm{deg} \pm 4.2$ & 0.86 \\
\hline & Subgroup A2: $13.2 \mathrm{deg} \pm 5.2$ & & 0.78 \\
\hline & Subgroup A3: $16.3 \mathrm{deg} \pm 8.2$ & & 0.56 \\
\hline \multirow[t]{3}{*}{ Loss of Kyphotic } & Subgroup A1: $10.7 \mathrm{deg} \pm 6.2$ & $6.2 \mathrm{deg} \pm 6.3$ & 0.034 \\
\hline & Subgroup A2: : $7.1 \mathrm{deg} \pm 7.4$ & & 0.056 \\
\hline & Subgroup A3: $6.1 \mathrm{deg} \pm 5.2$ & & 0.1 \\
\hline
\end{tabular}

Table 2: Comparing improvement in neurological outcome among both group

\begin{tabular}{|c|c|c|c|c|c|c|c|}
\hline \multirow{2}{*}{$\begin{array}{l}\text { Pre-op } \\
\text { grade }\end{array}$} & \multirow[t]{2}{*}{ Frankel } & \multirow{2}{*}{$\begin{array}{l}\text { No. of } \\
\text { patients }\end{array}$} & \multicolumn{5}{|c|}{ Frankel grade at 6th month follow up } \\
\hline & & & $\mathrm{A}(1)$ & $\mathrm{B}(2)$ & $\mathrm{C}(3)$ & $\mathrm{D}(4)$ & $\mathrm{E}(5)$ \\
\hline \multicolumn{8}{|c|}{ Group A } \\
\hline $\mathrm{A}(1)$ & & 6 & 4 & 2 & & & \\
\hline $\mathrm{B}(2)$ & & 1 & & & 1 & & \\
\hline$C(3)$ & & 6 & & & 2 & 2 & 2 \\
\hline $\mathrm{D}(4)$ & & 5 & & & & 3 & 2 \\
\hline $\mathrm{E}(5)$ & & 0 & & & & & \\
\hline Total & & 18 & & & & & \\
\hline \multicolumn{8}{|c|}{ Group B } \\
\hline $\mathrm{A}(1)$ & & 3 & 2 & 1 & & & \\
\hline $\mathrm{B}(2)$ & & 1 & & & 1 & & \\
\hline$C(3)$ & & 7 & & & 4 & 2 & 1 \\
\hline $\mathrm{D}(4)$ & & 3 & & & & 2 & 1 \\
\hline $\mathrm{E}(5)$ & & 0 & & & & & \\
\hline Total & & 14 & & & & & \\
\hline
\end{tabular}

In subgroup analysis at $6^{\text {th }}$ month follow up we found significantly lesser loss of kyphosis correction in subgroup A3 (Short-Segment Posterior Fixation with anterior column reconstruction) as compared to subgroup A1 (Short Segment Posterior Fixation only). Short-segment Posterior Fixation with index screw (subgroup A2) also decreases the loss of kyphosis correction at $6^{\text {th }}$ month follow up which is comparable with Short-segment posterior fixation with anterior column reconstruction (subgroup A3), which is comparable with the study conducted by Kim et al. ${ }^{[22]}$ Overall the radiological outcome in patients with Short-segment Posterior Fixation with anterior column reconstruction and Short-segment Posterior Fixation with index screw is similar to Long-segment Posterior Fixation (LSPF). However, a study conducted by Sapkas et al. ${ }^{[12]}$ Tezeren et al. ${ }^{[9]}$ and Alhemiary et al. ${ }^{[2]}$ showed significant differences among both shortsegment posterior fixation and long-segment posterior fixation group in term of loss of kyphosis correction. Our study showed no significant difference in terms of neurological and functional outcomes among both groups. Surgical site infection was encountered in two patients in the Long-segment Posterior Fixation group. No implant-related complications were encountered in both groups.

\section{Conclusion}

Short-segment Posterior Fixation (SSPF) is associated with significantly decreased duration of surgery and blood loss when compared to Long-segment Posterior Fixation (LSPF). Functional and neurological outcomes are comparable among both the groups. Loss of kyphosis correction in Short-segment Posterior Fixation (SSPF) may be decreased with an index screw or anterior column reconstruction.

\section{References}

1. Denis F. The three column spine and its significance in the classification of acute thoracolumbar spinal injuries. Spine. 

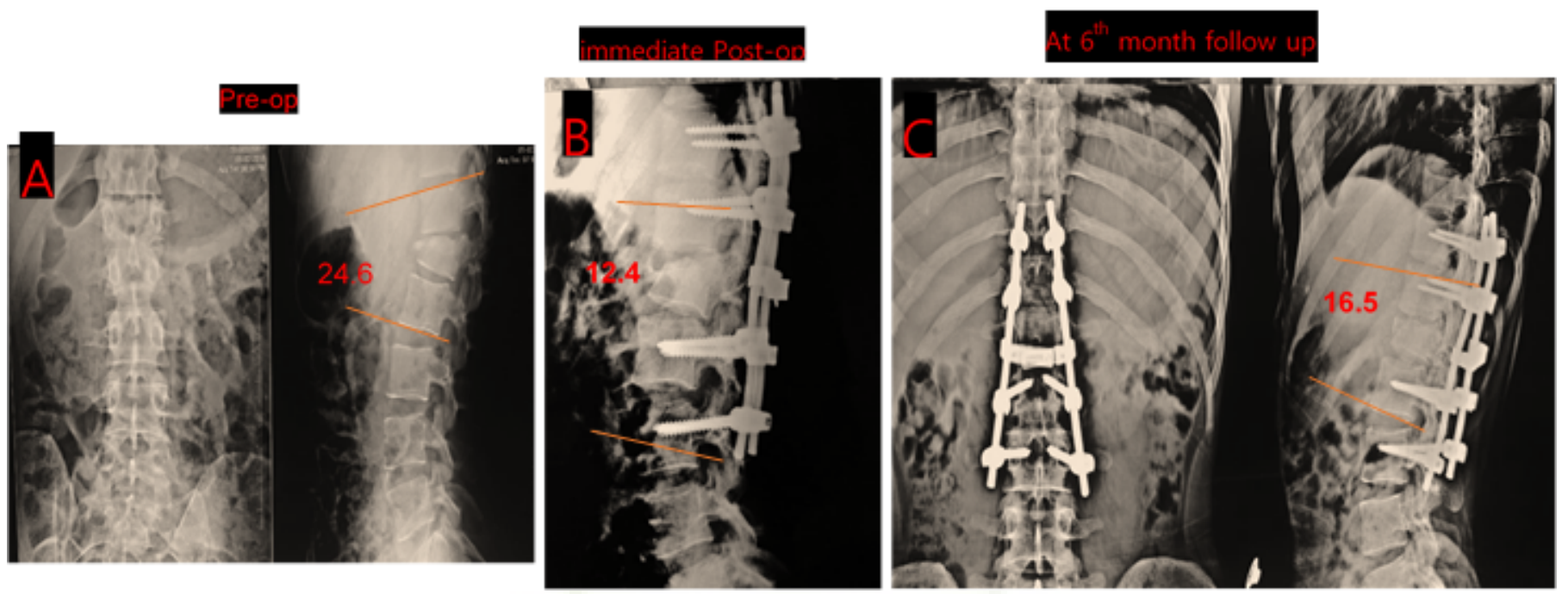

Figure 3: Showing case example of a24-year-old male with burst fracture L1 with Frankel A paraplegia which was managed with long-segment posterior fixation:- (A) -pre-operative plan radiograph showing decreased L1 vertebral body height with increased interpedicle distance in AP view which is suggestive of burst fracture L1 with kyphotic deformity of 24.6degree,(B) -plan radiograph postoperative showing long-segment posterior fixation with kyphosis angle 12.6 degrees, (C)- plan radiograph at 6th moth follow up showing kyphosis angle of 16.5 degree

1983;8(8):817-831. Available from: https://dx.doi.org/10. 1097/00007632-198311000-00003.

2. Alhemiary HA, and DFA. Short segment versus long segment posterior pedicular fixation of thoracolumbar fracture. J Fac Med Baghdad. 2017;59(3):204-208. Available from: https: //dx.doi.org/10.32007/med.1936/jfacmedbagdad.v59i3.2.

3. Hao D, Wang W, Duan K, Ma M, Jiang Y, Liu T, et al. TwoYear Follow-up Evaluation of Surgical Treatment for Thoracolumbar Fracture-Dislocation. Spine. 2014;39(21):E1284E1290. Available from: https://dx.doi.org/10.1097/brs. 0000000000000529.

4. Pellisé F, Barastegui D, Hernandez-Fernandez A, BarreraOchoa S, Bagó J, Issa-Benítez D, et al. Viability and long-term survival of short-segment posterior fixation in thoracolumbar burst fractures. Spine J. 2015;15(8):1796-1803. Available from: https://dx.doi.org/10.1016/j.spinee.2014.03.012.

5. Wood KB, Li W, Lebl DS, Ploumis A. Management of thoracolumbar spine fractures. Spine J. 2014;14(1):145164. Available from: https://dx.doi.org/10.1016/j.spinee.2012. 10.041 .

6. Carl AL, Tromanhauser SG, Roger DJ. Pedicle Screw Instrumentation for Thoracolumbar Burst Fractures and FractureDislocations. Spine. 1992;17(8):317-324. Available from: https://dx.doi.org/10.1097/00007632-199208001-00018.

7. Ebelke DK, Asher MA, Neff JR, Kraker DP. Survivorship Analysis of VSP Spine Instrumentation in the Treatment of Thoracolumbar and Lumbar Burst Fractures. Spine. 1991;16:S433-S433. Available from: https://dx.doi.org/10. 1097/00007632-199108001-00024.

8. McLain RF, Sparling E, Benson DR. Early failure of shortsegment pedicle instrumentation for thoracolumbar fractures.
A preliminary report. J Bone Joint Surg. 1993;75(2):162167. Available from: https://dx.doi.org/10.2106/00004623199302000-00002.

9. Tezeren G, Kuru I. Posterior Fixation of Thoracolumbar Burst Fracture: Short-Segment Pedicle Fixation Versus Long-Segment Instrumentation. J Spinal Disord Tech. 2005;18(6):485-493. Available from: https://dx.doi.org/10. 1097/01.bsd.0000149874.61397.38.

10. Altay M, Ozkurt B, Aktekin CN, Ozturk AM, Dogan Ö, Tabak AY. Treatment of unstable thoracolumbar junction burst fractures with short- or long-segment posterior fixation in magerl type a fractures. Eur Spine J. 2007;16(8):1145-1155. Available from: https://dx.doi.org/10.1007/s00586-007-03105.

11. Guven O, Kocaoglu B, Bezer M, Aydin N, Nalbantoglu U. The Use of Screw at the Fracture Level in the Treatment of Thoracolumbar Burst Fractures. J Spinal Disord Tech. 2009;22(6):417-421. Available from: https://dx.doi.org/10. 1097/bsd.0b013e3181870385.

12. Sapkas G, Kateros K, Papadakis SA, Brilakis E, Macheras G, Katonis P. Treatment of Unstable Thoracolumbar Burst Fractures by Indirect Reduction and Posterior Stabilization: Short-Segment Versus Long-Segment Stabilization. Open Orthopaed J. 2010;4(1):7-13. Available from: https://dx.doi. org/10.2174/1874325001004010007.

13. Dick W, Kluger P, Magerl F, Woersdörfer O, Zäch G. A new device for internal fixation of thoracolumbar and lumbar spine fractures: the 'fixateur interne'. Spinal Cord. 1985;23(4):225232. Available from: https://dx.doi.org/10.1038/sc.1985.38. 
14. Mikles MR, Stchur RP, Graziano GP. Posterior Instrumentation for Thoracolumbar Fractures. J Am Acad Orthop Surg . 2004;12(6):424-35. Available from: https://dx.doi.org/10. 5435/00124635-200411000-00007.

15. Aly TA. Short Segment versus Long Segment Pedicle Screws Fixation in Management of Thoracolumbar Burst Fractures: Meta-Analysis. Asian Spine J. 2017;11(1):150-160. Available from: https://dx.doi.org/10.4184/asj.2017.11.1.150.

16. Rommens PM, Weyns F, Calenbergh FV, Goffin J, Broos PL. Mechanical performance of the Dick internal fixator: a clinical study of 75 patients. Eur Spine J. 1995;4(2):104-109. Available from: https://dx.doi.org/10.1007/bf00278921.

17. McLain RF, Sparling E, Benson DR. Early failure of short-segment pedicle instrumentation for thoracolumbar fractures. A preliminary report. J Bone Joint Surg Am. 1993;75(2):162-7. Available from: https://dx.doi.org/0.2106/ 00004623-199302000-00002.

18. Rc S, Hb C. Posterior instrumentation and fusion for unstable fractures and fracture-dislocations of the thoracic and lumbar spine. A comparative study of three fixation devices in 70 patients. Spine (Phila Pa 1976). 1993;18(4):450-60.

19. Speth MJ, Oner FC, Kadic MA, de Klerk LW, Verbout AJ. Recurrent kyphosis after posterior stabilization of thoracolumbar fractures. 24 cases treated with a Dick internal fixator followed for 1.5-4 years. Acta Orthop Scand. 1995;66(5):406-410. Available from: https://dx.doi.org/10. 3109/17453679508995575.

20. Kramer DL, Rodgers WB, Mansfield FL. Transpedicular instrumentation and short-segment fusion of thoracolumbar fractures: a prospective study using a single instrumentation system. J Orthop Trauma. 1995;9(6):499-506. Available from: https://dx.doi.org/10.1097/00005131-199509060-00007.

21. A A, E A, M Y, A O, A S. Short-segment pedicle instrumentation of thoracolumbar burst fractures: does transpedicular intracorporeal grafting prevent early failure? Spine . 2001;26(2):213-217. Available from: https://dx.doi.org/10. 1097/00007632-200101150-00017.

22. Kim HS, Lee SY, Nanda A, Kim JY, Park JO, Moon SH. Comparison of Surgical Outcomes in Thoracolumbar Fractures Operated with Posterior Constructs Having Varying Fixation Length with Selective Anterior Fusion. Yonsei Med J. 2009;50(4):546-554. Available from: https://dx.doi.org/10. $3349 /$ ymj.2009.50.4.546.

Copyright: (C) the author(s), 2020. It is an open-access article distributed under the terms of the Creative Commons Attribution License (CC BY 4.0), which permits authors to retain ownership of the copyright for their content, and allow anyone to download, reuse, reprint, modify, distribute and/or copy the content as long as the original authors and source are cited.

How to cite this article: Singh A, Bali SK, Maji S, Ahuja K, Moger NM, Mittal S, Sarkar B, Kandwal P. Short Segment Versus Long Segment Posterior Pedicle Screws Fixation for Treatment of Thoracolumbar Burst Fracture: A Comparative Prospective Study. Asian J. Med. Res. 2020;9(2):1-6.

DOI: dx.doi.org/10.47009/ajmr.2020.9.2.OR1

Source of Support: Nil, Conflict of Interest: None declared. 